\title{
A Convenient Route to N-Acetyl-D-glucosamine-2-C-d and $\mathrm{N}$-Acetyl-D-mannosamine-2-C-d
}

\author{
L. SZILÁGyi \\ Department of Organic Chemistry, L. Kossuth University, Debrecen, Hungary \\ P. Herczegh \\ Antibiotics Research Group of the Hungarian Academy of Sciences, \\ L. Kossuth University, Debrecen, Hungary \\ and
}

Gy. BuJTÁs

Central Chemical Research Institute of the Hungarian Academy of Sciences, Budapest, Hungary

(Z. Naturforsch. 32b, 296-298 [1977]; received December 7, 1976)

Amino Sugars, C-Deuteration, ${ }^{1} \mathrm{H}$ NMR

\begin{abstract}
Title compounds were prepared through epimerisation of 2-acetamido-2-deoxy-D. glucose in NaOD. The isotopic purity of the products was determined by NMR and mass spectroscopy. The mechanism of epimerisation is briefly discussed.
\end{abstract}

In connection with our studies ${ }^{1}$ on the interaction of lysozyme with deuterium-labelled monosaccharide inhibitors, we needed gram quantities of 2-acetamido-2-deoxy-D-glucose-2-C-d (2) in fairly high isotopic purity. Ali and RICHaRdson ${ }^{2}$ proposed a rather complicated route for the synthesis of 2 . The well-known epimerisation ${ }^{3,4}$ of 2 -acetamido-2-deoxy-D-glucose (1) offers a much simpler alternative. This reaction takes place under basic conditions and results in a 4:1 mixture of the gluco and manno epimers, respectively. Coxon and HougH suggested $^{5}$, without experimental proof, the following plausible scheme for the mechanism of epimerisation.
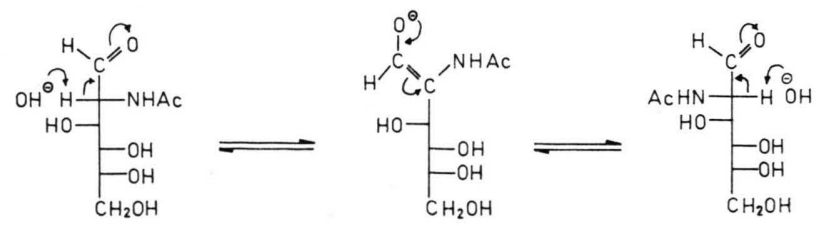

If this mechanism is correct, complete exchange between the sugar C-2 proton and water protons should occur during the epimerisation process. This is exactly what we observed. The anomeric proton

Requests for reprints should be sent to Dr. L. SzILÁGyi, Department of Organic Chemistry, H-4010 Debrecen, Hungary. doublet in the ${ }^{1} \mathrm{H}$ NMR spectrum of $1(\delta \sim 5.2$, $J_{12}=2.5 \mathrm{~Hz}$ ) began to collapse immediately when a $\mathrm{D}_{2} \mathrm{O}$ solution of 1 was made basic with $\mathrm{NaOD}$. This phenomenon indicated that fairly rapid proton exchange occurred at C-2 of 1. More detailed information could, however, be obtained by observing the ${ }^{1} \mathrm{H}$ NMR spectrum of 2 -acetamido-2-deoxy-Dmannose (7) under similar conditions. This spectrum (Fig. 1A) displays, in addition to the anomeric proton signals, well-resolved resonances for $\mathrm{H}-2$ ( $\alpha$ - and $\beta$-anomer) and H-3 ( $\alpha$-anomer). Since the spectrum of $\mathbf{1}$ is empty in this region the course of the epimerisation can be conveniently monitored through changes in the ${ }^{1} \mathrm{H}$ NMR spectrum of 7 . The intensity of the $\mathrm{H}-2$ signals decreased rapidly when $\mathrm{NaOD}$ was added to a solution of 7 in $\mathrm{D}_{2} \mathrm{O}$ with concomitant collapse of the H-1 (to singlets) and the H-3 (to a doublet) resonances. Fig. $1 \mathrm{~B}$ shows the ${ }^{1} \mathrm{H}$ NMR spectrum of the D-manno epimer (8), isolated pure from the reaction mixture.

The exact percentage of the deuterium incorporated could not be determined from this spectrum alone, however. A quantitative estimate was obtained from the ${ }^{1} \mathrm{H}$ NMR spectrum of 2 -acetamido1,3,4,6-tetra-O-acetyl-2-deoxy- $\beta$-D-glucopyranose $(6)$ prepared $^{6}$ from 2 . Comparison of the residual H-l doublet to the main H-1 "singlet" showed that 6 
contained $\sim 70-75 \%$ deuterium at C-2. The exact percentage was determined through ${ }^{2} \mathrm{H}$ NMR. For this purpose, 2-(acetyl-d-amino)-2-deoxy-D-glucopyranose-2-C-d (4) (and the D-manno analogue (9)) was prepared by treating 2-(acetyl-d-amino)-2deoxy-D-glucopyranose (3) with $\mathrm{NaOD}$. Compound 3 was obtained ${ }^{1}$ by $\mathrm{N}$-acetylation from 2 -amino-2deoxy-D-glucose using $\left(\mathrm{CH}_{2} \mathrm{DCO}\right)_{2} \mathrm{O}$. The deuterium content of 3 was $\geqslant 99 \%{ }^{1}$. A reliable ${ }^{2} \mathrm{H}$ intensity reference label was thus introduced into compound 2. Integration of the proton noise-decoupled FT ${ }^{2} \mathrm{H}$ NMR spectrum of $\mathbf{4}$ showed its deuterium content at C-2 to be $71 \pm 2 \%$.
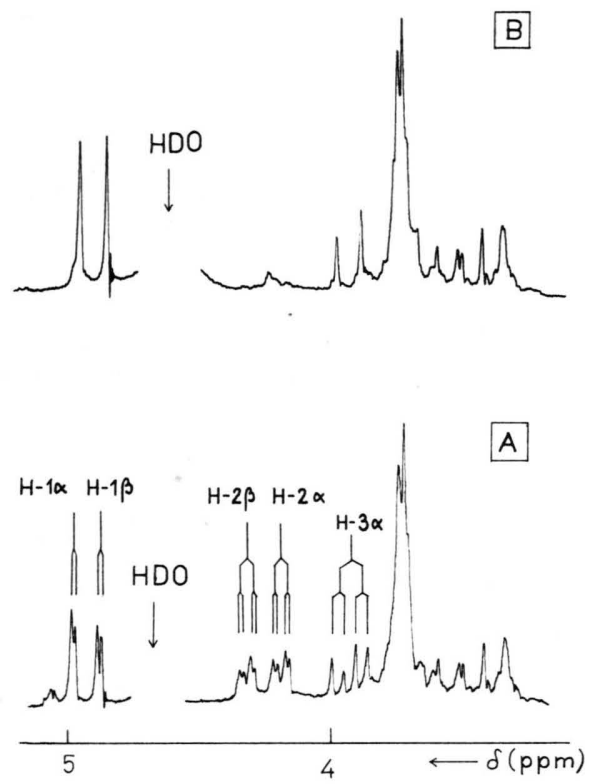

Fig. 1. Partial $100 \mathrm{MHz}{ }^{1} \mathrm{H}$ NMR spectra of 2 -acetamido-2-deoxy-D-mannose (7) (A) and 2-acetamido-2deoxy-D-mannose-2-C-d $\mathrm{d}_{1}(\mathrm{8})(\mathrm{B})$ in $\mathrm{D}_{2} \mathrm{O}$ solution.

Obviously, the dilution of $\mathrm{D}_{2} \mathrm{O}$ due to the five exchangeable protons in $\mathbf{1}$ (or $\mathbf{3}$ ) may have contributed considerably to the incomplete deuterium incorporation at C-2. When the exchangeable protons in 3 were replaced by deuteriums prior to epimerisation, integration of the D-2 signals against the $\mathrm{CO}-\mathrm{CH}_{2} \mathrm{D}$ signal in the ${ }^{2} \mathrm{H}$ NMR spectrum of 4 indicated $94 \pm 2 \% \mathrm{D}$ at $\mathrm{C}-2$. This figure was substantiated by mass spectral data of 2 -acetamido$1,3,4,6$-tetra-O-acetyl-2-deoxy- $\alpha$-D-glucopyranose2-C-d (5) obtained by epimerisation and subsequent acetylation from per-O,N-deuterated 1. Both EI and $\mathrm{CI}\left(\mathrm{NH}_{3}\right)$ mass spectra of $\mathbf{5}$ and its unlabelled counterpart were recorded and the abundance of their ions M-43, M-148, M-233 (EI), M+ 1 and $M+18$ (CI) compared (correction for the naturally occurring isotopes was carried out). The mean value of the $\mathrm{D}$ content was found to be $89 \pm 2 \%$ for each of these ions in 5 .

In conclusion, it can be stated that the high percentage of deuterium incorporation found by NMR and mass spectroscopy* provides strong support in favour of the mechanism advanced by Coxon and $\mathrm{HougH}^{5}$ for the base-catalysed epimerisation of amino sugars. On the other hand, this reaction is potentially useful for the preparation of amino sugars specifically labeled with tritium and possessing high specific activity.

This manuscript had been under preparation when the paper of SALO et al. ${ }^{7}$, reporting similar use of the epimerisation reaction, came to our attention.

\section{Experimental}

Compounds $\mathbf{5}$ and $\mathbf{6}$ were obtained by procedures described 8,6 for the preparation of the unlabelled compounds. 4 was prepared from $3^{1}$ by the procedure described below for $\mathbf{2}$.

\section{2-Acetamido-2-deoxy-D-glucopyranose-2-C-d (2)}

This compound was prepared essentially by the method of SPIVAK and Roseman ${ }^{9}$.

$10 \mathrm{~g}$ of 1 was lyophilised 3 times from $\mathrm{D}_{2} \mathrm{O}$ then dissolved with gentle warming $\left(30-35^{\circ} \mathrm{C}\right)$ in $25 \mathrm{ml}$ of $0.1 \mathrm{~mol} / \mathrm{dm}^{3} \mathrm{NaOD}$ in $\mathrm{D}_{2} \mathrm{O}$. The $\mathrm{pH}$ of the solution was 11-11.5. After standing at room temperature for $48 \mathrm{hrs}$ it was treated with BIO-RAD AG $50 \mathrm{~W}$ $\left(\mathrm{H}^{+}\right.$-form) cation exchange resin (to $\mathrm{pH}$ 5-5.5) and evaporated under reduced pressure until incipient crystallisation. $5.1 \mathrm{~g}$ of a white crystalline product was obtained; m.p. $203-205^{\circ} \mathrm{C},[a]_{\mathrm{D}}+47.8^{\circ}\left(\mathrm{H}_{2} \mathrm{O}\right.$, equilibrium). HoRTON ${ }^{6}$ gives for 1 m.p. $203-205^{\circ} \mathrm{C}$, $[\alpha]_{\mathrm{D}}+41^{\circ}$. Further $1.85 \mathrm{~g}$ was obtained in two crops from the mother liquors (overall yield $70 \%$ ). ${ }^{1} \mathrm{H}$ NMR $\delta 5.2 \mathrm{~s}, \mathrm{H}-1(\alpha) ; \delta 4.75 \mathrm{~s}, \mathrm{H}-1(\beta)$.

\section{2-Acetamido-2-deoxy-D-mannopyranose-2-C-d (8)}

The mother liquors from 2 were evaporated to dryness and worked up as described by KuHN and BASCHANG ${ }^{10}$. Crystallisation from water-aceton yielded $1.0 \mathrm{~g}$ (yield $10 \%$ ) of a product, m.p. ${ }_{125}-127^{\circ} \mathrm{C},[\alpha]_{\mathrm{D}}+8.9^{\circ}\left(\mathrm{H}_{2} \mathrm{O}\right.$, equilibrium). Lit. 9 gives for $7 \mathrm{~m}$.p. $128-129^{\circ} \mathrm{C},[\alpha]_{\mathrm{D}}+9.7^{\circ} \mathrm{C}$. The ${ }^{1} \mathrm{H}$ NMR spectrum of 8 is shown in Fig. $1 \mathrm{~B}$.

EI mass spectrum of $\mathbf{5}$ (the mass spectrum of the unlabeled compound was published $\left.{ }^{11}\right)$.

$m / e(\mathrm{I} \%): 348(0.6), 347(3.3), 346(1.2), 330(1.5)$, $329(0.4), \quad 319(1.1), \quad 318(0.2), \quad 289(0.5), \quad 288(2.3)$,

* The agreement between the NMR and mass spectral data can be regarded as satisfactory considering the integration accuracy of both methods. 
